\title{
A PHOTOELECTRIC DEVICE FOR MEASUREMENT OF LEAF AREAS ${ }^{1}$
}

\author{
L. S. Donovan, A. I. Magee and W. Kalbfleisch \\ Canada Department of Agriculture, Ottawa, Ontario
}

[Received for publication May 30, 1958]

\begin{abstract}
A device for the rapid measurement of leaf areas is described. Leaves are placed between a fliorescent light source, high in the red spectrum, and a photocell covered with an F29 red light filter. The reduction in output of the cell, as measured by a galvanometer, is interpreted in terms of area. The device has been successfully used in a genetic study of leaf size in birdsfoot trefoil.
\end{abstract}

\section{INTRODUCTION}

To carry out many investigations in the plant sciences a rapid and accurate means of determining the area of leaves is a necessity. The number of measurements to be made, the wide variations in leaf shape which occur, and the accuracy required often preclude the use of such laborious methods as printing the leaf outlines on light sensitive paper and measuring them with a planimeter or calculating area from linear measurements using geometric formulae. Realizing this, a number of workers $(1,2,3,4,5,6)$ have built and described photoelectric devices which they used in studies concerned with leaf size measurements. The principle involved is the direct relationship which exists between the area of a leaf placed between a light source and a photocell and the reduction in output of the cell due to part of the light being blocked off.

In the construction of one of these devices there are two main requirements to consider. Irradiation of the specimen stage should be as uniform as possible in order that "position effects" will be negligible and some provision should be made to compensate for the fact that most leaves are not entirely opaque but transmit some yellow-green light. In the device to be described here, these requirements, within acceptable tolerances, have been met by the use of a fluorescent light high in the red spectrum and a red light filter, features which have not been used in devices previously described.

\section{CONSTRUCTION DETAILS}

The structure of this device is shown in Figure 1.

The cabinet consists of two parts and is built of $\frac{3}{4}$-inch plywood. The lower part, the "light box", is a 26 -inch cube, inside measurement. This dimension, which is not critical, was determined by the space required to accommodate the fluorescent lamps on the under side of the box lid. The "light box" is painted white on the inside and has a piece of white blotting-paper tacked on the floor to improve diffusion of the light reflected through the specimen stage. Overheating of the lamps is prevented by the

\footnotetext{
1Joint contribution from the Forage Crops Division and the Field Husbandry, Soils and Agricultural Engineering Division, Canada Department of Agriculture, Ottawa, Ont.
} 

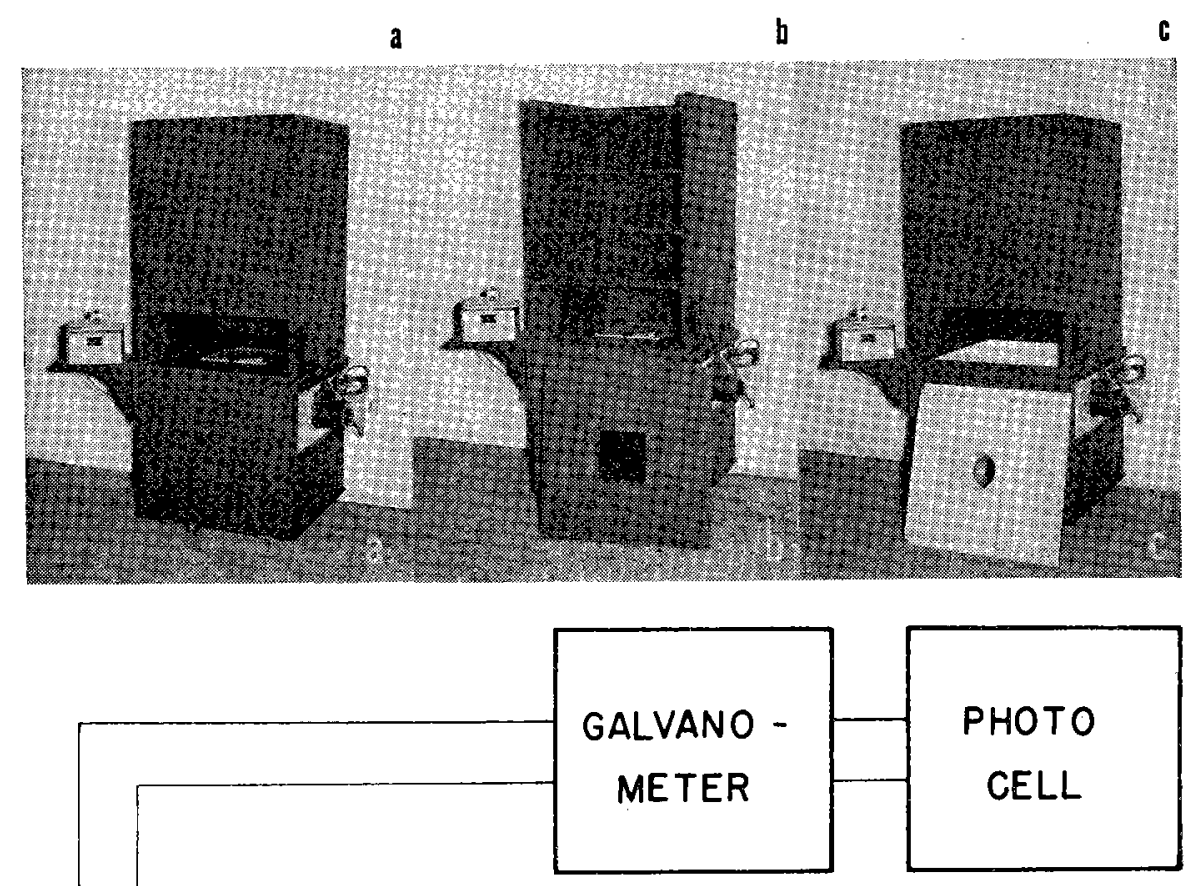

\author{
b. Cupola front and top removed. \\ c. Light box lid removed. \\ d. Circuit diagram.
}

FigURE 1. a. Device assembled.

circulation of air through slots cut in the walls. The "light box" lid has a hole 6 inches in diameter cut exactly in its centre. Fitted into this hole is a cylinder made of white blotting-paper which projects 1 inch below the fluorescent lamps.

The specimen stage consists of a piece of plate glass, $10^{\prime \prime} \times 12^{\prime \prime} \times 3 / 16^{\prime \prime}$, mounted in a metal frame on the upper side of the lid and centred over the 6-inch hole. Beneath this is placed a piece of 22-gauge galvanized iron of the same length and width, painted black and having a hole $5 \frac{3}{4}$ inches in diameter cut in its centre. Projection of the light through the hole in this thin plate ensures a well defined beam. A hinged glass plate, $8^{\prime \prime} \times 10^{\prime \prime} \mathrm{x}$ $3 / 16^{\prime \prime}$, is mounted over the specimen stage and isused to hold the leaves flat. 
The second part of the cabinet consists of a cupola, $26^{\prime \prime} \times 26^{\prime \prime} \times 36^{\prime \prime}$, the walls of which are continuous with those of the "light box". The height of the cupola, which determines the distance between the light source and photocell, should not be less than 36 inches. In the front of the cupola is a "working port" and above this is housed a series of four baffles, made of $\frac{1}{2}$-inch plywood with holes cut in the centres. The size of these holes should be slightly larger than the diameter of the light beam in use. On the under side of the cupola lid and exactly in the centre is mounted a photocell behind a red light filter, the latter being used to correct for leaf transparency.

\section{APPARATUS AND SPEGIFICATIONS*}

1. Fluorescent Lamps-8, F20T12, pink, 20 watts each.

2. Selenium Photocell-International Rectifier Corp., 6" diam., rated at $950 \mu$ a. at a light intensity of $100 \mathrm{ft}$. candles with an external resistance of 100 ohms.

3. Voliage Regulator $-250 \mathrm{VA}, 110 \mathrm{~V}, 60$ cycles.

4. Autotransformer -3 amps, $\mathrm{O}-130 \mathrm{~V}$ output, 60 cycles.

5. Galvanometer-Kipp A-70, scale deflection of $1 \mathrm{~mm}$. at 1 metre for a current of 0.001 microamps, and internal resistance of $80 \mathrm{ohms}$, an external resistance of $100-2000 \mathrm{ohms}$ and five sensitivity ranges.

6. Light Filter-Canadian Kodak, F29, deep red, spectral transmission $610 \mathrm{~m} \mu$ to the infra red.

*The mention of specific instruments or trade names is made for purpose of identification only and does not imply any endorsement by the authors.

TABle 1-Calibration Data (Galvanometer REAdiNGS IN SCALE Units), SHOWING EFFECT OF POSITION OF CALIBRATION PIECE IN A LIGH'T BIAM $5 \frac{3}{4}$ INCHES IN DIAMETER

\begin{tabular}{|c|c|c|c|c|c|c|c|c|}
\hline \multirow{2}{*}{$\begin{array}{l}\text { Known } \\
\text { area } \\
\text { (sq. cm.) }\end{array}$} & \multicolumn{8}{|c|}{ Position of calibration piece in light beam } \\
\hline & Centre & Left & Right & Front & Rear & Average & Range & $\%$ Error $^{2}$ \\
\hline 5 & 7.4 & 7.3 & 7.5 & 75 & 76 & 75 & 03 & 30 \\
\hline 10 & 14.4 & 14.1 & 14.1 & 14.3 & 14.2 & 14.2 & 0.3 & 2.1 \\
\hline 15 & 21.8 & 21.6 & 21.5 & 21.5 & 21.8 & 21.6 & 0.3 & 1.4 \\
\hline 20 & 29.2 & 29.0 & 28.9 & 28.9 & 29.0 & 29.0 & 0.3 & 1.0 \\
\hline 25 & 36.2 & 35.9 & 35.9 & 35.9 & 36.0 & 36.0 & 0.3 & 0.8 \\
\hline 30 & 43.5 & 43.2 & 43.1 & 43.1 & 43.3 & 43.2 & 0.4 & 0.9 \\
\hline 35 & 50.5 & 50.3 & 50.3 & 50.3 & 50.3 & 50.3 & 0.2 & 0.4 \\
\hline 40 & 57.4 & 56.8 & 56.8 & 56.9 & 57.0 & 57.0 & 0.6 & 1.0 \\
\hline 45 & 64.4 & 64.0 & 64.0 & 64.0 & 64.2 & 64.1 & 0.4 & 0.6 \\
\hline 50 & 71.6 & 71.3 & 71.3 & 71.2 & 71.4 & 71.4 & 0.4 & 0.6 \\
\hline 55 & 78.1 & 77.9 & 77.9 & 77.8 & 77.8 & 77.9 & 0.3 & 0.4 \\
\hline 60 & 85.0 & 85.0 & 85.0 & 84.9 & 84.9 & 85.0 & 0.1 & 0.1 \\
\hline 65 & 92.0 & 91.8 & 91.8 & 91.7 & 91.9 & 91.8 & 0.3 & 0.3 \\
\hline 70 & 98.4 & 98.1 & 98.1 & 98.0 & 98.4 & 98.2 & 0.4 & 0.4 \\
\hline 75 & 105.5 & 105.4 & 105.3 & 105.3 & 105.4 & 105.4 & 0.2 & 0.2 \\
\hline Average & 57.0 & 56.8 & 56.8 & 56.8 & 56.9 & 56.8 & 0.2 & 0.4 \\
\hline
\end{tabular}

- ${ }^{1}$ Calibration pieces were carefully cut from black fibreboard approximately $0.6 \mathrm{~mm}$. in thickness.

${ }^{2}$ Expressed as per cent of the maximum reading in the series which, in most cases, is that for the centre
position. 


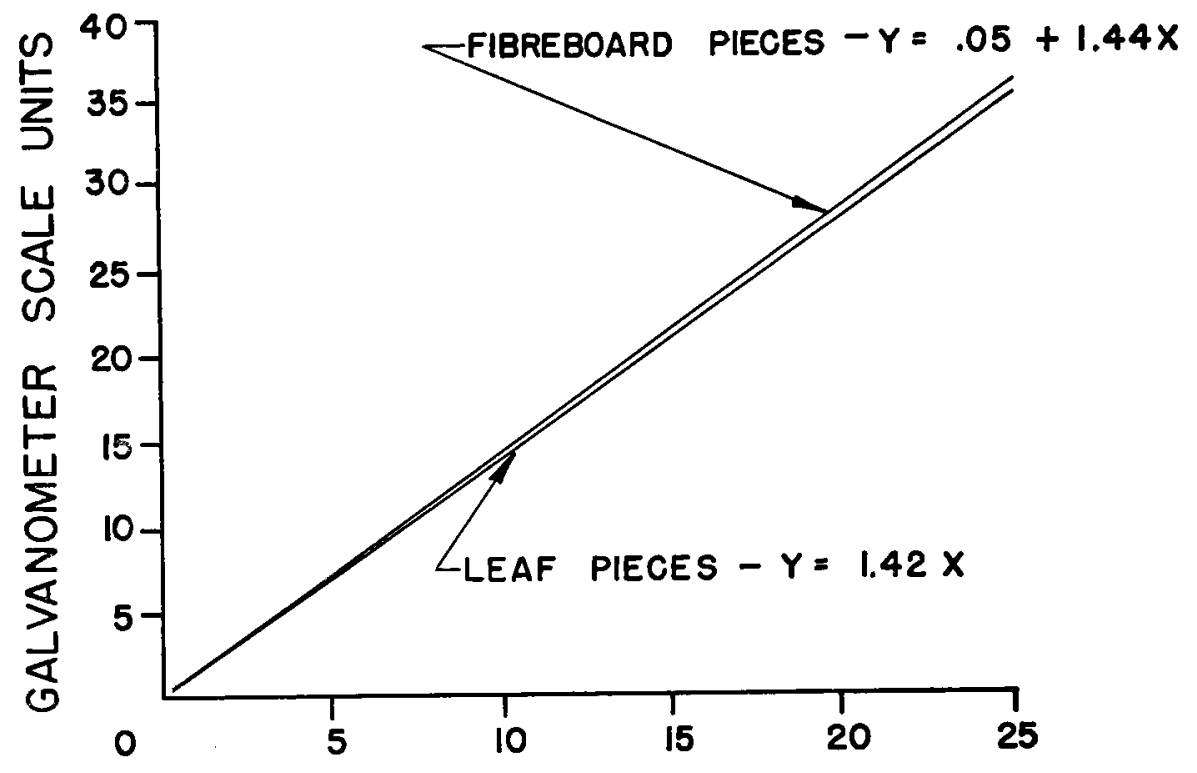

AREA IN SQUARE CM.

FIGURE 2. A comparison of calibration curves using fibreboard and leaf pieces; curves fitted by the least squares method.

\section{OPERATION}

The instruments used with this device are connected as shown in Figure 1. Before the lights are turned on the galvanometer reading is zeroed at 200 on the reversed 200-0 scale. This reversed scale provides a direct relationship between the scale reading and the area of the leaves placed in the light beam.

The lights must be allowed to warm up for 10 minutes. The galvanometer reading is then brought to zero on the reversed scale by adjusting the light intensity through adjustments in the output voltage of the autotransformer. After each measurement when the leaves are cleared from the specimen stage this zero reading should be checked and the light intensity readjusted if necessary. Usually, adjustment at the other end of the scale need only be made every hour or so of operation.

\section{PERFORMANCE}

The data in Table 1 show that irradiation of the specimen stage is very uniform. The light intensity in the central part of the beam is slightly higher than that nearer the edges but this difference is not large. In practice the sample of leaves is arranged from the centre of the beam outwards, the result of which is to minimize the error due to position. For samples larger than $20 \mathrm{sq} . \mathrm{cm}$., the percentage error due to position effect would not exceed 1 per cent. For samples smaller than this, a smaller light beam could be used along with a higher light intensity and/or a more sensitive range on the galvanometer. 
The upper limit of the optimum sample size is set by the practical consideration of the time required to arrange the leaves in the light beam. With trefoil leaves it has been found that speed of placement in a light beam $5 \frac{3}{4}$ inches in diameter usually starts to drop off when the sample size approaches $75 \mathrm{sq} . \mathrm{cm}$.

From Figure 2 it is seen that the differences between the calibration curves for leaf and fibreboard pieces are very small. The difference at the origin is 0.05 scale units while the slope of the curve for leaf pieces is 98.6 per cent of that for fibreboard pieces. These differences are due to such effects as faulty cutting of calibration pieces, errors in scale reading, the slight differences in light intensity at different locations in the beam and possibly a certain amount of uncorrected leaf transparency. Because of problems connected with the cutting and handling of a large number of 1 sq. $\mathrm{cm}$. leaf pieces, it was not practical to compare these curves beyond the $0-25 \mathrm{sq} . \mathrm{cm}$. range. However, this comparison is sufficiently extensive to confirm the similarity of the curves and establish the fact that for practical purposes a complete calibration curve based on fibreboard pieces may be used for the conversion of instrument readings from leaf measurements.

To date the device has only been used in a genetic study of leaf size in birdsfoot trefoil. It has proved to be a very satisfactory instrument for this purpose.

\section{ACKNOWLEDGEMENTS}

The authors wish to acknowledge with thanks the advice received from P. D. Carman, of the National Research Council, Ottawa, Ontario.

\section{REFERENCES}

1. Frear, Donald E. H. Photoelectric apparatus for measuring leaf areas. Plant Physiol. 10:569-574. 1935.

2. Hibbard, R. P., B. H. Grisby, and W. G. Keck. A low light intensity photoelectric device for the measuring of leaf areas. Proc. Michigan Acad. Sciences, Arts and Letters, pp. 141-147. 1937.

3. Kramer, Paul J. An improved photoelectric device for measuring leaf areas. Amer. Botany 24:375-376. 1937.

4. Miller, E. E., C. A. Shadbolt, and Leroy Holm. Use of an optical planimeter for measuring leaf area. Plant Physiol. 31:484-486. 1956.

5. Mitchell, John W. Measurement of the area of attached and detached leaves. Science 83:334-336. 1936.

6. Withrow, Robert B. A photoelectric device for the rapid measurement of leaf area. Agr. Research 50:637-643. 1935. 